\title{
HISTÓRIA E IDENTIDADE NA FICÇÃO DE JOSÉ EDUARDO AGUALUSA
}

\author{
Maurício Silva ${ }^{*}$ \\ Universidade Nove de Julho
}

\begin{abstract}
Resumo: Nos países africanos lusófonos, a produção literária quase sempre esteve vinculada aos eventos históricos, vinculo que resulta num complexo processo de construção de uma identidade cultural. O próprio desenvolvimento da literatura africana lusófona sugere essa perspectiva, na medida em que história e identidade tornam-se, a partir do século XX, conceitos fundamentais para a constituição de uma literatura independente. Analisando a produção literária africana lusófona contemporânea, não há como negar nem sua procedência anticolonialista, no plano histórico, nem sua vinculação com os conceitos de nacionalismo, no âmbito identitário. Assim, se de alguma maneira essa literatura mostra-se vinculada a um projeto mais amplo de luta anticolonial, ela apresenta também uma espécie de desígnio nacionalista, promovendo, desse modo, o entrecruzamento entre história e identidade. Desse modo, a literatura lusófona produzida no continente africano chega ao presente século, por um lado, consolidando essas duas matrizes ideológicas responsáveis por sua constituição e desenvolvimento e, por outro lado, buscando ressignificar a relação que ambos os conceitos estabelecem entre si. $\mathrm{O}$ presente artigo procura analisar a relação entre história e identidade na literatura angolana, em especial na prosa de ficção de José Eduardo Agualusa. O artigo destaca o modo de representação da história angolana em sua produção literária.
\end{abstract}

Palavras-chave: Literatura Angolana. Prosa de ficção. José Eduardo Agualusa. História africana. Identidade

\section{Introdução}

Desde a década de 1970, as relações entre Portugal e suas ex-colônias sofreram profundas alterações, a partir das quais se promoveu uma revisão dos conceitos que davam sustentação pragmática e ideológica a essas relações, sobretudo no que se refere à tão debatida questão colonial. Atualmente, quando se discute abertamente as diretrizes e os resultados do amplo processo de globalização por que passam todas as nações politicamente organizadas, faz-se ainda mais necessário uma amplificação de nossas perspectivas culturais, redirecionando nossos interesses para realidades pouco contempladas pelas abordagens \section{(i) $(9)$}

Esta obra está licenciada sob uma Licença Creative Commons.

\footnotetext{
* Doutor em Letras Clássicas e Vernáculas pela Universidade de São Paulo. Professor do Programa de Mestrado e Doutorado em Educação na Universidade Nove de Julho (São Paulo). E-mail: maurisil@gmail.com.
} 
culturalistas tradicionais.

Nesse contexto, destaca-se a necessidade de retomada das relações político-culturais entre os países de língua portuguesa, relevando o aspecto peculiar de suas respectivas culturas. Sob essa ótica, compreende-se a importância assumida, no presente momento, pelo estudo das literaturas africanas de expressão portuguesa, por meio do qual se busca promover uma aproximação entre culturas que, historicamente, sempre estiveram vinculadas.

Pode-se dizer, sem risco de cometer alguma impropriedade, que nos países africanos lusófonos a produção literária quase sempre esteve vinculada aos eventos históricos, vinculo que resulta num complexo processo de construção de uma identidade cultural. O próprio desenvolvimento da literatura africana lusófona sugere essa perspectiva, na medida em que história e identidade tornam-se, a partir do século XX, conceitos fundamentais para a constituição de uma literatura independente. Desse modo, a literatura lusófona produzida no continente africano chega ao presente século, por um lado, consolidando essas duas matrizes ideológicas responsáveis por sua constituição e desenvolvimento e, por outro lado, buscando ressignificar a relação que ambos os conceitos estabelecem entre si.

Com efeito, analisando a produção literária africana lusófona contemporânea, não há como negar nem sua procedência anticolonialista, no plano histórico, nem sua vinculação com os conceitos de nacionalismo, no âmbito identitário. Assim, se de alguma maneira essa literatura mostra-se vinculada a um projeto mais amplo de luta anticolonial, ela apresenta também uma espécie de desígnio nacionalista, promovendo, desse modo, o entrecruzamento entre história e identidade.

Esse fato pode ser superiormente percebido na produção de José Eduardo Agualusa, autor que se afirma, no atual cenário da literatura africana de expressão portuguesa, como uma de suas mais importantes vozes, não sem razão, fazendo da conjunção entre história e identidade marca indelével de sua produção ficcional.

\section{Percursos da história na produção de Agualusa}

Embora considerado por antropólogos e arqueólogos uma espécie de berço da humanidade, é principalmente com o advento da expansão ultramarina que o continente africano passa por uma exploração sistemática, primeiro ao longo de sua costa, posteriormente no interior. Apesar de haver, desde o princípio da história africana, muitos povos desenvolvidas, com tecnologia própria, sua população foi considerada, pelos europeus, primitiva, tendo sido escravizada e, parte dela, deslocada para a América Latina. Como afirmam Carlos Serrano e Maurício Waldman, 
o continente africano foi, inegavelmente, o mais desqualificado pelo pensamento ocidental. Ainda que a imagem da África tenha variado ao longo do tempo em decorrência de diferentes formas de relacionamento estabelecida com os seus povos, é indiscutível que o continente foi, mais do que qualquer outro, laureado pelo pensamento ocidental com imagens particularmente negativas e excludentes (SERRANO; WALDMAN, 2007, p. 24)

Com efeito, com a expansão ultramarina e, posteriormente, o imperialismo europeu, já na segunda metade do século XIX, o continente foi sistematicamente repartido entre as potências ocidentais da Europa, ocasionando mudanças na constituição geopolítica do mundo de conseqüências dramáticas até os dias atuais. O resultado final, depois de muitas lutas e conflitos de toda ordem, foi a independência do continente africano, deixando, contudo, marcas indeléveis no imaginário europeu, como explicam Ana Lopes e Luiz Arnaut:

sob o rótulo de sociedades primitivas e tradicionais foram elaboradas reflexões que apresentavam as culturas africanas como estáticas, sua população como detentora de uma forma de pensamento irracional, mítico ou fantástico. Paralelo a isso, a história ia sendo escrita por militares, missionários e viajantes que, sem suporte acadêmico, registravam impressões e conhecimentos, tentavam explicar as culturas, migrações e intercâmbios. Nessa produção, que contém tanto reflexões simplistas e toscas quanto excelentes relatos e observações, podemos identificar formas de convivência na África, assim como o imaginário europeu (LOPES; ARNAUT, 2005, p. 37)

Essa política imperialista de ocupação do continente africano ganhou forma, principalmente, com a célebre Conferência de Berlim (1884-1885), por meio do qual a África passou a ser dividida de acordo com os interesses políticos e econômicos das nações européias, refletindo uma situação de conflito que já se vinha desenhando desde o Tratado de Berlim, em 1878 (BOURGIN, 1967; DEBIDOUR, 1929; HOBSBAWM, 1988). Tais acontecimentos não poderiam ter-se dado sem graves conseqüências até os dias atuais, provocando, como já se afirmou uma vez "ondas de choque políticas, econômicas e sociais que até hoje são sentidas na África" (MACKENZIE, 1994, p. 10).

Fenômenos históricos que se sucederam àqueles aqui lembrados, bem como suas conseqüências socioculturais, são superiormente representados pela literatura de Agualusa, a qual tem na ficcionalização da história uma de suas marcas estéticas mais recorrentes.

É o que se pode constatar, por exemplo, em A Feira dos Assombrados e Outras Estórias Inverossímeis, romance que se desenvolve na pacata cidade de Dondo, no final do século XIX, por onde passa o famoso rio Quanza. Como em outros romances de sua lavra, o autor parte de fatos históricos - muitas vezes colocados, nesse romance, sob a forma de epígrafe dos capítulos - para exercitar a narrativa no domínio da ficção, num feliz entrecruzamento entre literatura e história. Evidentemente, em se tratando de um texto ficcional, o texto não dispensa alguns artifícios narrativos, mas quase sempre aliados ao percurso histórico que lhe 
serve de fundo, como é o caso da memória: narrado em primeira pessoa, o enredo segue o trajeto livre da memória, que resgata fatos e pessoas da cidade de Dondo, memória esta que desencadeia os fatos - reais ou imaginários - vividos por seus habitantes. Conferir um estatuto de verdade aos acontecimentos narrados é, no final das contas, perder boa parte do encanto literário promovido pela fantasia da imaginação, já que, entre o imaginário e a realidade, a narrativa se desdobra em infinitas surpresas ao leitor.

Talvez não seja o caso, por isso, de estabelecer marcas divisórias que separem sua produção ficcional em fases distintas, a partir da adoção - em maior ou menor grau - do substrato histórico como elemento propulsor de sua narrativa, mas parece evidente que enquanto em suas primeiras obras Agualusa apresenta uma linearidade estrutural e um tratamento temático que o aproxima, sutilmente, da tradição angolana da novela de costumes que vai, pelo menos, de Alfredo Troni a Pepetela, mas sem o engajamento deste, nem o documentarismo daquele; nas obras seguintes essa tendência parece ceder espaço a outros aspectos da realidade africana, os quais passam a concorrer, no plano da narrativa, com a representação dos fenômenos históricos. Isto não quer, de modo algum, dizer que em suas obras iniciais Agualusa não tenha alçado vôos em mundos fantasiosos, imaginários, substancialmente ficcionais: já em A Feira dos Assombrados é possível adentrar um universo bastante inusitado, que não poucas vezes tangencia o realismo maravilhoso latino-americano, isso sem considerar que, a partir de Nação Crioula (1998b), o "descritivismo" histórico cede lugar para uma expressão mais livre, menos calcada na realidade, em benefício da imaginação criativa.

Embora a questão da representação histórica esteja presente em Fronteiras Perdidas, coleção de pequenos contos espirituosos e humorísticos, quase sempre revelando agilidade narrativa e sensibilidade no tratamento das evidências humanas e apresentando a complexidade da sociedade angolana por meio de uma fina ironia, o lastro histórico de sua produção pode ser mais bem percebida em Estação das Chuvas (1996). Com efeito, segundo Nelson Pestana, nesse romance Agualusa entrelaça várias histórias entrecortadas, mesclando ficção e história de modo a revelar questões do tempo em que os fatos narrados se passam e/ou para desvelar figuras míticas da história angolana (PESTANA, 2006).

Assim, prevalece nesse romance a narrativa de cunho histórico, em que se misturam o entrecho biográfico às cenas fantasiosas de extração ficcional, inclusive com a utilização de expedientes aparentemente avessos à narrativa ficcional (como a entrevista, as notas de rodapé etc.), tudo isso contribuindo para um inesperado caráter híbrido do texto. Acrescente- 
se a isso o fato de que, revisitando ficcionalmente o movimento pela independência de Angola, Agualusa cria uma obra que, não fosse a ousadia estrutural e a ironia do estilo, enquadrar-se-ia na mais pura tradição da literatura militante que vai, em Angola, de Agostinho Neto a Pepetela: narrando a vida da poetisa Lídia do Carmo Ferreira, Agualusa elege como pano de fundo de seu enredo a história dos movimentos políticos de resistência e libertação angolanos, revelando suas contradições mais intrínsecas, até chegar à triste constatação final, proferida pelo narrador, de que “este país morreu!”(AGUALUSA, 1996, p. 259). Com razão, fala-se, ao se referir a abordagem da história por A Estação das Chuvas, numa espécie de história de confrontos, que revela uma "intenção generalizada de desmistificar o Passado, fazê-lo dialogar com o Presente, para se projetar o Futuro" (MATA, 2001, p. 220).

Mas é com dois outros romances de sua safra que Agualusa parece atingir o auge dessa tendência à ficcionalização da história, plasmada na narração de fatos e acontecimentos "verídicos" da história angolana.

Com A Conjura (1998a) Agualusa retorna a Luanda do final do século XIX para discutir, naquele contexto, tanto as divisões ideológicas que separam monarquistas (como Afonso, Exequiel etc.) e republicanos (como Carmo Ferreira, Afonso Vieira Dias, Alfredo Trony, Arantes Braga etc.) quanto questões relacionadas à colonização portuguesa e à independência de Angola. Com passagens humorísticas e artifícios intertextuais (Alfredo Trony, por exemplo, torna-se personagem do romance, escrevendo, a certa altura da narrativa, a novela Nga Muturi), o romance tem na linguagem um de seus mais relevantes componentes estéticos, uma vez que ela desempenha papel fundamental na composição do enredo, revelando acirrado embate entre o universo da palavra e o do silêncio: não por mero acaso, Alfredo Trony aconselha a Ezequiel "severa abstinência verbal" (AGUALUSA, 1998a, p. 15), fazendo uma irônica distinção entre a fala dos príncipes e o coaxar dos sapos; da mesma maneira, Alicinha insiste para que o papagaio Manaus fale a palavra fraternidade, embora ele só proferisse termos de baixo calão, sendo que a própria Alicinha é definida mais a partir da linguagem do que propriamente por outros traços que ela possa apresentar; finalmente, falar muito e irracionalmente torna-se, na trama, algo impertinente, já que ao "devolver" a esposa (Dona Féfa) para a mãe (Xica da Ilha), Carmo Ferreira recomenda-lhe que corte a língua da filha.

A abordagem da história, contudo, não está presente apenas em passagens factuais narradas nas entrelinhas do enredo. Ela se afirma, antes, como um antagonismo ideológico 
que coloca em destaque o clássico confronto entre civilização e barbárie. Com efeito, problematizando a trama narrativa, impõe-se, logo de início, a oposição entre colonizado e colonizador, que se percebe no questionamento de Arantes Braga: “de que nos vale a nós sermos iguais a um povo miserável, analfabeto e bruto? E que nos pretende civilizar enviando-nos o pior lixo das suas sarjetas sociais: os seus ladrões, assassinos e prostitutas?" (AGUALUSA, 1998a, p. 26).

Nesse como em outros contextos, descritos pelo livro, o conceito de civilização corresponde, direta ou indiretamente, ao de colonização, a qual é vista, sem rebuços, como elemento desarticulador da dinâmica social angolana, como sugere, por exemplo, os fins de Pedro Saturnino de Souza e de Ezequial, mortos pela civilização.

Procurando desfazer as fronteiras que separam os continentes africano, europeu e americano e catalisando sentimentos diversos, quase sempre imbuídos da ideologia libertária, A Conjura mescla, com propriedade, ficção e história, como sugere Maria Teresa Salgado, para quem "a obra de Agualusa amplia o leque de indagações no diálogo entre ficção e história, pois encena discussões que enfocam o papel desempenhado pelos africanos e portugueses em momentos e espaços bastante carregados de tensão, conflito e ambivalência" (SALGADO, 2006, p. 177). Isso tudo é particularmente perceptível, ainda segundo a mesma autora, em $A$ Conjura, romance no qual

\footnotetext{
a releitura da história não servirá apenas como forma de questionar a versão oficial dos fatos, fazendo emergir o que foi silenciado (afinal, já sabemos que não há senão versões) mas também para relativizar quaisquer narrativas legitimadoras, reavaliando a relação entre história e as inúmeras possibilidades oferecidas pelo imaginário, seja o da tradição ocidental seja o da tradição oral (SALGADO, 2006, p. 187).
}

Análise semelhante à que acabamos de fazer aqui pode ser aplicada também a sua obra Nação Crioula, romance epistolar criado a partir de cartas que o protagonista - Fradique Mendes - escreve alternadamente à madrinha (Madame de Jouarre), à amante (Ana Olímpia) e ao amigo e confidente (Eça de Queirós). Mesclando um humor irônico e descrições que beiram a uma singular "antropologia", pautada no senso comum, suas epístolas revelam esteticamente falando - uma feliz incorporação de motivos populares à narrativa, resultando num paulatino envolvimento de Fradique Mendes - português educado, de estirpe nobre com os naturais da terra e com o próprio país. Assim, o romance situa-se num mundo - a despeito do tom realista que o conforma - quase fantástico, algo rústico, mas em constante ebulição, uma ebulição humana, rácica, vital. Deslocando-se como um protagonista perplexo por temas divergentes, viajando por continentes diversos - viagens de que suas missivas dão 
contundente testemunho -, Fradique Mendes logra aproximar, em lances de genialidade irônica, civilizações aparentemente díspares: "Mas o que é a civilização? Entre o cavaleiro melancólico que freqüenta os salões de Madame de Jouarre, minha gentil madrinha, e o remoto canibal do Alto Amazonas, não existe séria divergência moral, apenas gastronómica" (AGUALUSA, 1998b, p. 117).

De fato, reside aí o impulso meta-histórico do romance, na medida em que, desfazendo as diferenças historicamente construídas, sua obra focaliza, como quer Ana Beatriz Barel, o momento de ruptura do Império Português no Atlântico Sul, na medida em que "ilustra, metaforicamente, o ponto de virada na história do sistema colonial, atestando a construção da República no Brasil e antecipando a desconstrução definitiva do Império português" (BAREL, 2009, p. 97). Trata-se, sem dúvida nenhuma, de um dos pontos altos da ficcionalização da história promovida por Agualusa, projeto que não dispensa - antes, faz questão de aguçar - a relação dialógica de extração paródica (SANTILLI, 2003).

Oposto complementar de Iracema de Alencar, Nação Crioula afirma-se, assim, como o desfecho de um longo percurso de construção de uma identidade marcada pela miscigenação: se dos primeiros contatos entre o europeu (Martim) e o nativo indígena (Iracema) nasce o brasileiro Moacir, do contato entre o europeu (Fradique) e o africano (Ana Olímpia) nasce a brasileira Sophia, representando definitivamente a união dos três continentes e consolidando a idéia de uma nação crioula. A carta com que o autor encerra seu livro dirigida a Eça de Queirós, em outubro de 1888 - é exemplar como crítica e consciência das relações entre os três continentes, já assinalando outro aspecto fundamental de sua literatura, analisada a seguir: a questão da identidade.

\section{A identidade na encruzilhada da trama}

A questão da identidade - seja ela relacionada, de forma independente, à língua, à história, à literatura; ou, numa incontornável mescla, a outros elementos - está presente na produção ficcional de Agualusa desde seus primeiros escritos, mas ganha maior densidade nas obras mais recentes, quando o autor faz desse conceito um dos elementos centrais na sua reflexão acerca da cultura africana lusófona.

Como no caso da representação histórica, analisada acima, pode-se dizer que o seu Fronteiras Perdidas já antecipa, em muitos aspectos, algumas questões mais bem resolvidas nas obras seguintes, uma vez que esse texto não dispensa a presença de identidades múltiplas, sejam elas insólitas (na figura de um lagarto, em "Dos pingos do riso"), míticas (na figura do feiticeiro, em "Os mistérios do mundo"), forjadas (na figura sugestivamente chamada de B.B. 
em “A pobre...”), misteriosas (na figura de Plácido Domingo, em narrativa homônima) ou enigmáticas (nas figuras de Raquel, em "As fronteiras perdidas" ou do homem que, no sonho do narrador, muda de aparência, em "Não há mais lugar...”).

Identidades múltiplas, como dissemos, parecem ser, aliás, um conceito bastante apropriado ao século XXI, em que, conforme explana Stuart Hall, a idéia de identidade passa por um processo de transformação que se caracteriza principalmente pela crítica à idéia de uma identidade integral, originária e unificada. Nesse sentido, completa o autor, o conceito de identidade emerge como uma concepção que não assinala um núcleo estável do eu, mas, ao contrário, observa-se que

as identidades não são nunca unificadas; que elas são, na modernidade tardia, cada vez mais fragmentadas e fraturadas; que elas não são, nunca, singulares, mas multiplamente construídas ao longo de discursos, práticas e posições que podem se cruzar ou ser antagônicos. As identidades estão sujeitas a uma historicização radical, estando constantemente em processo de mudança e transformação (HALL, 2000, p. 108).

É o que se observa, por exemplo, além do já citado Fronteiras Perdidas, no seu Manual Prático de Levitação (2005), narrativa marcada pelo inesperado e insólito - que procura misturar um cru realismo à fantasia que, não raro, beira ao nonsense -, cujos contos exploram a fundo a temática da identidade, seja ela individual ou coletiva, evidenciando os inúmeros conflitos que se inscrevem na relação eu-outro, perspectiva, aliás, igualmente presente em alguns textos de A Substância do Amor e Outras Crônicas (2000).

O encontro como o outro, a marcar de modo substantivo a questão identitária, talvez esteja mais bem representada em seu romance Um Estranho em Goa (2000), obra em que o autor transforma uma experiência concreta (sua estada em Goa) em experiências subjetivas, internalizadas, que nascem das impressões colhidas do contato com uma realidade totalmente nova e diferente. Nesse romance, de uma maneira um pouco mais trágica e realista que em outros livros, Agualusa aborda a questão da identidade sob o prisma dos descendentes portugueses que vivem em Goa, dando ao tema, portanto, um contorno mais político. Como já assinalou Sónia Melo, as narrativas de viagens presentes na ficção de Agualusa acabam servindo como "pretexto para ele próprio reflectir sobre o seu lugar no mundo, a sua condição identitária" (MELO, 2012, p. 09). A busca do eu, seu sentido ontológico e, sobretudo, seu lugar no mundo, expressa-se ainda, na ficção de Agualusa, por meio do caldeamento da questão identitária à língua portuguesa, ora tida como a língua dos brasileiros, ora como uma língua transplantada no continente africano, em constante conflito com falares nativos e regionais, como se pode perceber em diversas passagens de As Mulheres de meu Pai (2007). 
Com efeito, não sem razão a língua, para Peter Burke, pode ser tomada como "uma das manifestações mais importantes de identidade coletiva" (BURKE, 1995, p. 94).

Mais do que qualquer outra obra de Agualusa, a questão da identidade está melhor representada e discutida - dentro do conjunto de sua produção ficcional - em seus romances O Ano em que Zumbi tomou o Rio (2002) e O Vendedor de Passados (2004).

O Ano em que Zumbi tomou o Rio narra a história de Francisco Palmares (comerciante de armas traficadas de Angola), que vive no Rio de Janeiro, onde inesperadamente encontra o jornalista Euclides Matoso, supostamente morto há algum tempo em Angola, mas que, na verdade, saíra clandestinamente de seu país e agora trabalhava como jornalista em Lisboa, gozando férias no Brasil. Tendo sido levado por Francisco Palmares para conhecer os morros cariocas, Euclides Matoso encontra-se ainda com Bartolomeu Catiavala (antigo companheiro, também fugido de Angola) e com Jararaca, conhecido traficante e matador do Morro da Barriga e que tencionava provocar uma revolução no Rio de Janeiro, a fim de dar o poder aos negros. Com efeito, pressionado cada vez mais pela polícia, Jararaca e seus homens conseguem ocupar as principais posições da cidade, prender o governador e criar um verdadeiro caos no Rio de Janeiro. A sublevação é sufocada, e Jararaca desaparece, sem que ninguém soubesse para onde teria ido e se ainda estaria vivo.

Com capítulos quer funcionam como se fossem pequenas cenas cinematográficas, simultâneas ou que se sucedem, criando uma perspectiva fragmentada, mas que consegue se articular numa unidade temática, a narrativa tem na questão racial um de seus principais ingredientes, apresentando, por meio da figura de Francisco Palmares, a visão do angolano acerca desse problema, o qual define o Brasil como "um país de negros escravizados" (AGUALUSA, 2002, p. 41). Tal visão contrasta com a perspectiva de Jararaca, representando a visão do brasileiro, segundo a qual quem nasce no morro tem grande possibilidade de "envelhece(r) sem jamais deixar de ser escravo" (AGUALUSA, 2002, p. 52).

É, portanto, ligada ao problema racial que a questão da identidade de impõe no livro, já que se vincula não apenas a perspectivas diferentes, por meio das quais o negro é retratado, mas também a modos diversos de representar esse problema, expresso ora no presépio formado por negros, de Eusébio Matoso; ora na indefinição fenotípica de Jararaca (negro, pardo, moreno escuro); ora ainda na letra do rap "Preto de Nascença", de Jacaré. Contudo, para além do tema racial, a questão identitária surge de modo mais saliente no fato de o romance assinalar as possíveis intersecções - culturais, históricas, políticas - entre as realidades brasileira e angolana, com tamanha habilidade, que se torna difícil demarcar uma 
distinção segura entre as duas nações, algo aliás já presente, in germine, em seu premiado romance Nação Crioula.

Obra em que a violência parece adentrar até mesmo as entranhas da narrativa ficcional, erigindo um discurso ágil e intertextual, compondo uma trama transgressora, embora linear em sua essência, $O$ Ano em que Zumbi tomou o Rio faz da alegoria um traço marcante de seu texto, associando uma narratividade dinâmica e contundente à recorrente questão da identidade em sua produção.

Tão recorrente que atinge seu ápice no inusitado $O$ Vendedor de Passados, história fantástica, que narra a saga de Félix Ventura, nome sugestivo para a atividade da personagem, um vendedor de passados, isto é, um fabricante de árvores genealógicas, fotos de ancestrais, pergaminhos antigos, enfim, tudo o que possa conferir ao seu cliente um passado nobre, embora "falso". Entre idas e vindas inesperadas, discute-se no romance não apenas aspectos da história recente de Angola, mas principalmente o impreciso conceito de identidade, já pressuposto na figura inusitada de um narrador-personagem que não é nada mais, nada menos do que uma... osga. Assim, ao escolher uma osga (espécie de lagartixa, que desempenha papel fundamental na discussão, presente na obra de forma latente, acerca do conceito de identidade), o autor sugere um olhar isento de qualquer envolvimento do narrador com a essência demasiadamente humana da questão identitária: enquanto ser irracional, deplacé, a osga está, supostamente, imune às questões "existencialistas" inscritas na trajetória dos demais personagens, a despeito de, inesperadamente, o enredo sugerir que ela teria sido, anteriormente (em outra vida?) um ser humano, carregando portanto consigo traços de uma angústia existencial, seja de alguém inutilmente à procura por um interlocutor, seja de alguém dotado de um humano remorso por não ter amado.

Assim, a cada passo da história, desdobra-se uma infinidade de possibilidades reflexivas, tornando $O$ Vendedor de Passados quase um romance filosófico, quando não existencialista, em que a identidade afirma-se como jogo de imagens refletidas em infinitos espelhos, tornando-se, portanto, um simulacro da realidade e fazendo confundirem-se verdade e mentira, fato e ficção, essência e aparência, ser e não-ser...

Se, como diz uma personagem, “a verdade é improvável” (AGUALUSA, 2004, p. 132), a fábula passa a ocupar o lugar da realidade, fazendo com que tudo se relativize e com que os pólos, aparentemente díspares, se atraiam e se igualem: "eu dou-lhe uma verdade impossível, você dá-me uma mentira vulgar e convincente" (AGUALUSA, 2004, p. 185). Assim, narrando a história de um autêntico vendedor de passados - ainda que se trate de um 
passado fabricado, um passado institucional - o autor aprofunda a questão da identidade angolana, procurando forjar-lhe uma tradição à la Borges (com o homem criando seus próprios precursores), clave temática já apontada na epígrafe do romance, retirada do próprio autor argentino: "Se tivesse de nascer outra vez escolheria algo totalmente diferente. Gostaria de ser norueguês. Talvez persa. Uruguaio não, porque seria como mudar de bairro" (AGUALUSA, 2004, p. V)

Presente ao longo de todo o romance, a questão da identidade dialoga ainda, bem de perto, com o tema da temporalidade, este vinculado de modo indelével à existência das personagens do texto: a necessidade de ter para si uma identidade verossímil, por exemplo, faz com que José Buchmann busque ansiosamente sua própria história, apropriando-se de um passado convincente. Mas, evidentemente, trata-se de um passado criado, falso, construído e reconstruído sob a forma de fábula por Félix Ventura. Nesse sentido, ocorre uma completa inversão na correlação temporal: em vez de a história inscrever-se na memória, como resultado do vivido, é a memória que emerge, na narrativa, como resultado da história, mas de uma falsa história, de uma fábula: "o que aconteceu à minha mãe?” (AGUALUSA, 2004, p. 41), pergunta um atônito José Buchmann, ao que responde Félix Ventura, depois de sinuosa narrativa: “acha-me com cara de Sherazade?" (AGUALUSA, 2004, p. 46). Vendedor de falsas identidades - ou melhor dizendo, de passados -, os quais logo se tornam "verdades" absolutas, preenchendo o vazio que cada um carrega em si mesmo, Felix Ventura também acaba sofrendo as conseqüências dessa manipulação do tempo, ao ver-se, ele mesmo, em dúvida acerca de sua própria identidade: "efabulo tanto, ao longo do dia, e com tal entusiasmo, que por vezes chego à noite perdido no labirinto das minhas próprias fantasias" (AGUALUSA, 2004, p. 125). Este fato torna-se tanto mais dramático, quanto mais nós comparamos a situação de José Buchmann, que - apesar de humano - é um ser sem passado e memória, os quais necessitam ser artificialmente construídos, com a do narrador, que - apesar de osga - é um ser cujo passado e memória permanecem intactos: "a única coisa que em mim não muda é o meu passado: a memória do meu passado humano" (AGUALUSA, 2004, p. 59). Ora, dialogando com a temporalidade, a questão da identidade traz ainda em seu bojo, sem que se explicite este fato, uma perspectiva cristã, que rege o silogismo exposto na célebre exortação bíblica do memento (memento homo: quia pulvis est et in pulverem reverteris), segundo o qual nós somos o que fomos no passado e o que seremos no futuro. Trata-se, em suma, da relatividade da concepção de tempo, exposta na reflexão do narrador: "Que idade terá? Talvez sessenta, e nesse caso cuidou muito bem do corpo a vida inteira, ou quarenta, 
quarenta e cinco, e então deve ter atravessado anos de profundo desespero" (AGUALUSA, 2004, p. 40).

Conceito do qual emerge um conflito entre o verdadeiro e o falso, a identidade migra, no romance, das personagens para a realidade circundante, seja fundamentando fenomenologicamente a compreensão da história (para Félix Ventura a história pode ser criada pela ação do homem, como ocorre com a escritura de $A$ Vida Verdadeira de um Combatente, em que até mesmo a falsa memória passa a ter validade), seja na leitura semiológica da Cidade do Cabo, com suas palmeiras falsas, "um logro no qual apetece acreditar" (AGUALUSA, 2004, p. 148). Nesse sentido, a identidade passa a ser compreendida como simulacro, espécie de virtualidade "enganosa", em que Verdade e Mentira se equivalem, tornam-se conceitos absolutamente permutáveis e relativizados por uma realidade impressionantemente volátil, a ponto de, a certa altura do romance, toda a história concernente ao passado de José Buchmann ir-se tornando verdadeira e adquirindo irrefutável credibilidade. A identidade, agora, passa a ser atributo da memória, mas de uma memória artificial, construída, como dissemos, como simulacro, a fim de satisfazer nossa contemporânea necessidade de uma identidade instantânea, como nos ensina Baudrillard:

já não temos tempo de buscar uma identidade nos arquivos, na memória, nem num projeto ou no futuro. Precisamos de uma memória instantânea, de ligação imediata, espécie de identidade publicitária que possa acontecer no mesmo instante (BAUDRILLARD, 1990, p. 30).

\section{Conclusão}

Evidentemente, a questão da história e da identidade em literatura é muito mais complexa do que este ensaio pode sugerir. São, antes de tudo, conceitos que estão em contínua transformação, como aliás a própria produção literária lusoafricana a que estão aqui associados, a qual, depois de um claro pendor militante e engajado, teria derivado

\footnotetext{
para a tendência de contestar, finalmente, a tradição realista, engagée, documentalista e ideo-política, sem que, todavia, isso significasse o abandono desse filão que a própria realidade histórica e política e a condição social e cultural do escritor continuavam a prescrever [...] a temática e os espaços social e cultural patenteados nos textos passaram a alargar-se consideravelmente, apresentando desde o amor e a angústia existencial, às vivências do poder estabelecido (LARANJEIRA, 1997, p. 88).
}

Isto, evidentemente, sem nos esquecermos dos experimentalismos formais e do trabalho minucioso que se tem feito com a linguagem, a qual passa a representar, na produção mais recente, Agualusa incluso, uma etapa de superação de seu viés marcadamente ideológico, como já afirmou Russel Hamilton (HAMILTON, 1981). Desse modo, a literatura 
passa a ser também, na opinião que Rita Chaves tece a respeito de Agualusa (e também de Pepetela) (CHAVES, 2005), um instrumento para se conhecer o próprio país e a própria cultura, motivo pelo qual parte significativa da produção ficcional angolana irá se dedicar à pesquisa histórica como base da criação, com incursões num passado que, de certo modo, resgata sua identidade.

Esses são aspectos que não apenas elevam essa produção à condição de uma literatura de primeira grandeza, mas reforçam ainda mais sua vocação a uma perspectiva artística que não prescinde das noções basilares de identidade e de história.

\section{Referências}

AGUALUSA, José Eduardo. Estação das Chuvas. Lisboa: Don Quixote, 1996. . A Conjura. Lisboa: Don Quixote, 1998a. . Nação Crioula. Rio de Janeiro: Gryphus, 1998b. . A Substância do Amor e Outras Crônicas. Lisboa: Don Quixote, 2000. . O Ano em que Zumbi tomou o Rio. Rio de Janeiro: Gryphus, 2002. . O Vendedor de Passados. São Paulo: Companhia das Letras, 2004. . Manual Prático de Levitação. Rio de Janeiro: Gryphus, 2005. . As Mulheres de meu Pai. Rio de Janeiro: Língua Geral, 2007.

BAREL, Ana Beatriz Demarchi. A Descontrução do Império e a Construção da Republica em Nação Crioula, de José Eduardo Agualusa. Nonada. Letras em Revista, Porto Alegre, v. 12, p. 94-103, 2009.

Disponível

em: http://seer.uniritter.edu.br/index.php/nonada/article/viewFile/104/76. Acesso em: 23 de outubro de 2012)

BAUDRILLARD, Jean. A Transparência do Mal. Ensaios sobre os Fenômenos Extremos. São Paulo: Papirus, 1990.

BOURGIN, Georges. La Troisième République. 1870-1914. Paris: Armand Colin, 1967.

BURKE, Peter. A Arte da Conversação. São Paulo: Unesp, 1995.

CHAVES, Rita. O passado presente na literatura angolana. In: CHAVES, Rita. Angola e Moçambique. Experiência colonial e territórios literários. São Paulo: Ateliê, 2005, p. 45-62.

DEBIDOUR, A. Histoire Diplomatique de l'Europe. La Paix Armée (1878-1914). Paris: Félix Alcan, 1929. 
HALL, Stuart. Quem precisa da identidade?. In: SILVA, Tomaz Tadeu da (Org.). Identidade e Diferença. A Perspectiva dos Estudos Culturais. Petrópolis: Vozes, 2000.

HAMILTON, Russel G. Literatura Africana. Literatura Necessária: Angola. Lisboa: Edições 70, 1981.

HOBSBAWM, Eric J. A Era dos Impérios. 1875-1914. Rio de Janeiro: Paz e Terra, 1988.

LARANJEIRA, Pires. Língua e Literatura nos Países Africanos de Língua Oficial Portuguesa. In: GALANO, Ana Maria et al (Orgs.). Lingua Mar: Criações e Confrontos em Português. Rio de Janeiro, Funarte, 1997, p. 83-99.

LOPES, Ana Mônica; ARNAUT, Luiz. História da África. Uma Introdução. Belo Horizonte: Crisálida, 2005.

PESTANA, Nelson. A história na história em Angola: Henrique Abranches e José Eduardo Agualusa. In: CHAVES, Rita; MACEDO, Tânia. Marcas da Diferença. As Literaturas Africanas de Lingua Portuguesa. São Paulo: Alameda, 2006, p. 227-241.

MACKENZIE, John. A partilha da África. São Paulo: Ática, 1994.

MATA, Inocência. A verdade da literatura: a propósito de Estação das Chuvas. In: MATA, Inocência. Literatura Angolana: Silêncios e Falas de uma Voz Inquieta. Lisboa: Mar Além, 2001, p. 218-225.

MELO, Sónia. Viagem a Goa: Agualusa e a Tradição Orientalista. In: IV Congresso Internacional da Associação Portuguesa De Literatura Comparada, Vol. 1, 2004, Évora. Anais eletrônicos. Évora, 2004. Disponível em: $<$ http://www.eventos.uevora.pt/comparada/VolumeI/VIAGEM\%20A\%20GOA.pdf $>$ Acesso em $20 / 03 / 2012$.

SALGADO, Maria Teresa. José Eduardo Agualusa: Uma Ponte entre Angola e o Mundo. In: SEPÚlVEDA, Maria do Carmo; SALGADO, Maria Teresa (Orgs.). África \& Brasil: Letras em Laços. São Caetano do Sul: Yendis, 2006.

SANTILLI, Maria Aparecida. O romance angolano: marcos e marcas. In: LEÃO, Ângela Vaz (Org.). Contatos e Ressonâncias. Literaturas Africanas de Língua Portuguesa. Belo Horizonte: PUCMINAS, 2003, p. 341-361.

SERRANO, Carlos; WALDMAN, Maurício. Memória d'África. A Temática Africana em Sala de Aula. São Paulo: Cortez, 2007.

[Recebido em fevereiro de 2015 e aceito para publicação em maio de 2015]

\section{History and identity in José Eduardo Agualusa fiction}

Abstract: In Portuguese-speaking African countries, literary production was almost always linked to historical events. It results from a complex process of building a cultural identity. The development of Portuguese-speaking African literature suggests that history and identity become, from the twentieth century, fundamental concepts for the establishment of an 
independent literature. This article analyses the relations between history and identity in Angolan literature, especially in José Eduardo Agualusa fiction. This article points out the mode of representation of Angolan history in literary production of José Eduardo Agualusa. Keywords: Angolan literature. Fiction. José Eduardo Agualusa. History. Identity.

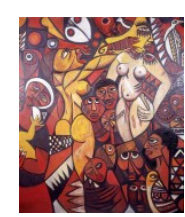

